\title{
Aprender a dançar tango em Buenos Aires: processos de transmissão e políticas culturais locais ${ }^{1}$
}

\author{
Learning to dance tango in Buenos Aires: transmission \\ processes and local cultural policies
}

\section{Hernán Morel}

Hernán Morel tem licenciatura e doutorado em Antropologia Social pela Faculdade de Filosofia e Letras da Universidade de Buenos Aires. Como professor de Folclore Geral, leciona em cursos de graduação e pós-graduação na área de Antropologia. É pesquisador do Consejo Nacional de Investigaciones Científicas y Técnicas (Conicet) e atua em temas relacionados às artes populares, performances, políticas culturais e patrimoniais, com foco na pesquisa da dança de tango em Buenos Aires.

\section{Resumo}

De modo geral, neste artigo, desenvolveremos algumas reflexões relacionadas ao ensino e aprendizado do tango na cidade de Buenos Aires no período pósditatorial. Consideramos que esse período foi acompanhado pelo gradativo ressurgimento do tango em nível local, portanto interessa-nos vincular o processo de ensino da dança a um conjunto de intervenções culturais produzidas durante esse período. Referimo-nos a uma sequência de ações, projetos e políticas culturais públicas que visavam favorecer o ensino e a transmissão do tango. Para isso, enfatizaremos algumas características singulares dessas atividades de intervenção, levando em consideração que as narrativas atuais em torno do ressurgimento do tango dançado costumam invisibilizar tais iniciativas culturais. Na tentativa de superar tais invisibilizações, destacaremos o papel desempenhado por certos atores envolvidos, especialmente os(as) professores(as) e milongueros(as), em relação às novas gerações que se aproximavam pela primeira vez do tango dançado.

Palavras-chave: Tango, Dança, Políticas Culturais, Patrimônio Intangível.

Traduzido por Maria Pilar Cabanzo. 


\section{Abstract}

In this article, we will develop some reflections related to teaching and learning tango dance in the city of Buenos Aires, in the post-dictatorship period. Considering that this period was accompanied by the gradual local resurgence of tango dance, we are interested in linking the process of dance teaching to a set of cultural interventions produced in this period. We refer to a sequence of public cultural actions, projects and policies aimed at favoring the teaching and transmission of tango dance. For doing so, we will emphasize some singular characteristics of these intervention activities, taking into consideration that the current narratives around the resurgence of the danced tango usually make such cultural initiatives imperceptible. To overcome such preclusion, we will highlight the role played by certain actors involved, especially the teachers and milongueros(as), in relation to the new generations which were approaching the danced tango for the first time.

Keywords: Tango, Dance, Cultural Policies, Intangible Heritage.

De modo geral, neste artigo, desenvolveremos algumas reflexões relacionadas ao ensino e aprendizado do tango na cidade de Buenos Aires no período pós-ditatorial. Consideramos que esse período ${ }^{2}$ foi acompanhado pelo gradativo ressurgimento do tango em nível local, portanto interessa-nos vincular o processo de ensino da dança a um conjunto de intervenções culturais produzidas durante esse período. Referimo-nos a uma sequência de ações, projetos e políticas culturais públicas que visavam favorecer o ensino e transmissão do tango. Para isso, enfatizaremos algumas características singulares dessas atividades de intervenção, levando em consideração que as narrativas atuais em torno do ressurgimento do tango dançado costumam invisibilizar tais iniciativas culturais (CAROZZI, 2012; MOREL, 2012). Na tentativa de superar tais invisibilizações, destacaremos o papel desempenhado por certos atores envolvidos, especialmente os(as) professores(as) e milongueros(as) ${ }^{3}$, em relação às novas gerações que se aproximavam pela primeira vez do tango dançado.

\footnotetext{
Na Argentina, o governo democrático retornou em 1983, a partir da posse de Raúl Ricardo Alfonsín como presidente.

3 Milongueros e milongueras são termos emic (nativos) utilizados pelos participantes das milongas para referir-se às pessoas que são assíduas frequentadoras desses eventos.
} 
É importante assinalar que, antes do período pós-ditatorial, não era comum que os adeptos à dança utilizassem instituições de ensino formais para aprender tango (PUJOL, 1999; MOREL, 2011; CAROZZI, 2015). Em outras palavras, o aprendizado, com exceções, não estava fortemente associado a estabelecimentos dedicados ao ensino. Como evidenciado nas narrativas de antigos milongueros, especialmente aqueles que dançavam antes de meados da década de 1980, a transmissão da dança ocorria nos clubes sociais ou no próprio núcleo familiar, portanto, a formação em dança era desenvolvida a partir de relações de amizade, família ou vizinhança. Como sugeriremos aqui, justamente poucos anos após o retorno da democracia, esse modo de transmissão foi afetado consideravelmente e surgiram outras práticas de ensino, tendo como base novos âmbitos de formação para transmitir a dança.

Inicialmente e para compreender esse processo com maior detalhe, no presente artigo, traçaremos as circunstâncias da prática social da dança na década de 1980 em Buenos Aires, descrevendo brevemente o contexto histórico e os processos sociais que contornaram essa prática popular. Posteriormente, faremos um percurso por algumas ações e políticas culturais as quais, como veremos, foram significativas no processo de ensino e aprendizado da dança a nível local a partir da pós-ditadura. Por fim, abordaremos a execução de um projeto oficial iniciado em 2004, relacionado à dança e à transmissão de saberes dos “velhos milongueros", denominado Academia de Estilos de Tango Argentino (Aceta). No decorrer da análise, apresentaremos algumas das principais iniciativas implementadas na cidade de Buenos Aires em termos de políticas culturais. Como estratégia de análise, traremos diferentes narrativas e trajetórias de ensino de milongueros(as), dançarinos(as) e professores(as) de tango que protagonizaram tais iniciativas.

\section{A DANÇA SOCIAL DO TANGO NA DÉCADA DE 1980}

A partir da década de 1960, o panorama popular do tango em Buenos Aires foi profundamente afetado. Distintas circunstâncias sociopolíticas e 
transformações culturais ${ }^{4}$ provocaram que os clubes sociais, salas e confiterías que frequentemente realizavam milonga ${ }^{5}$ diminuíssem em quantidade e assiduidade de público. Como efeito imediato, o tango ficou restrito a circuitos exclusivos e com escassa renovação de gerações. Isso trouxe como consequência uma "racha" no processo de transmissão da dança entre as novas gerações que rejeitavam-na (e que privilegiavam, em grande medida, outros estilos e danças populares, como o rock ou o folclore) e aqueles que vivenciaram, na juventude, as épocas de glória e auge do tango dançado das décadas de 1940 e 1950.

Desse modo, no início da década de 1980, as milongas mal subsistiam e somente alguns poucos grupos de milongueros(as) e amadores(as), na sua maioria pessoas mais velhas, continuavam dançando tango na cidade. A opinião de muitos desses milongueros mais velhos era que a dança de "pista" ou social estava "desaparecendo", pois os jovens não a valorizavam o bastante e nem sequer eram estimulados a praticá-la ${ }^{6}$. Como resultado da escassa renovação de gerações evidenciada no tango, com o retorno do governo democrático em 1983, espalhou-se um imaginário sobre esse gênero popular que o entendia como anacrônico, estagnado e fatalmente enterrado no passado.

Diante das circunstâncias pouco propícias para o ressurgimento da dança, de que maneira ela veio reaparecer, sendo transmitida às novas gerações? Existe uma ideia muito arraigada em relação ao ressurgimento da dança no período pós-ditatorial. Com efeito, diferentes especialistas e pessoas bastante ligadas ao tango (milongueros(as), dançarinos(as), músicos, historiadores(as) e jornalistas) costumam entender o espetáculo Tango argentino enquanto acontecimento paradigmático, sendo uma espécie de elo entre duas épocas. O espetáculo Tango argentino ${ }^{7}$ foi idealizado e dirigido por Claudio Segovia

\footnotetext{
${ }^{4}$ Para uma análise detalhada desse processo socio cultural, ver Pujol (1999) e Carozzi (2015).

5 As milongas como espaços de dança de tango na cidade de Buenos Aires existem pelo menos desde o início do século XX. Entendemos como "milonga" um local e evento onde as pessoas se reúnem para dançar tango e outros estilos musicais.

6 O documentário de Jorge Zanada, Tango Baile Nuestro, retrata a opinião de alguns desses milongueros e milongueras. Disponível em: https://bit.ly/2Int433. Acesso em: 2 mar. 2014.

7 É possível assistir a algumas cenas do espetáculo em: https://bit.ly/2v8bHLd. Acesso em: 4 abr. 2014.
} 
e Héctor Orezolli, tendo sua estreia no Teatro de Chatelet, em Paris, em 1983. Surpreendentemente, Tango argentino foi recebido com grande entusiasmo e sucesso na cidade parisiense, por isso, o espetáculo chegou inclusive a ser apresentado na Broadway em 1986 e passou por diferentes cidades do mundo até chegar em Buenos Aires, pela primeira vez em 1992.

Poderíamos afirmar que o relato ${ }^{8}$ em torno do espetáculo de Tango Argentino fundamenta seu "sucesso" e repercussão a partir da atração que exerceu no público estrangeiro', numa época em que o tango representava uma atividade artística e cultural que pouco chamava a atenção no contexto internacional. Entretanto, como assinalado em trabalhos anteriores (MOREL, 2012), esse relato sobre um espetáculo internacional de tango acabou invisibilizando diferentes acontecimentos e ações culturais produzidos localmente na década de 1980 e no início da de $1990^{10}$. De modo geral, tal desatenção desconhece ou minimiza o papel desempenhado por um conjunto de intervenções e políticas culturais locais, as quais, como sugeriremos a seguir, possibilitaram a ampliação de novos atores e segmentos sociais identificados e voltados para a prática da dança. Desse modo, para melhor compreender esse processo, analisaremos as narrativas e trajetórias de alguns milongueros(as) e professores(as), particularmente aqueles envolvidos com o ambiente da dança de tango nesse período.

\footnotetext{
8 Elinor Ochs (2000) afirma que o relato é um gênero narrativo específico que costuma trazer interpretações de acontecimentos passados mais do que descrições dos mesmos. Assim, os relatos apresentam escolhas mais do que espelhos da realidade.

9 Na construção do relato de Tango Argentino, identificamos uma espécie de explicação causal (OCHS, 2000), a partir da qual acredita-se que o atual interesse pela dança a nível local, nacional e internacional estaria marcado pela importância que esse espetáculo teve no exterior.

${ }^{10}$ A partir de uma análise das danças da Índia, Allen (1997) busca problematizar os discursos sobre o "ressurgimento" da dança. O autor afirma que o uso intencional e celebratório tende a naturalizar processos históricos complexos que envolvem diversos agentes e formas de exercer o poder.
} 


\section{POLÍTICAS CULTURAIS LOCAIS: NOVOS ÂMBITOS PARA O ENSINO DA DANÇA}

De modo geral, diversos autore ${ }^{11}$ caracterizaram as políticas culturais desenvolvidas no contexto da década de 1980, destacando a importância que ganhou a recuperação de espaços públicos, a participação popular e a confluência de práticas artísticas a partir da volta da democracia, após uma das ditaduras mais dramáticas vividas na Argentina. A respeito do tango, a conjuntura do retorno do governo democrático despertou um incipiente interesse pela dança, como lembra a dançarina e professora Olga Bessio:

de repente, surgiu uma espécie de otimismo coletivo e muitas pessoas se animaram a fazer o que queriam. Algumas dessas pessoas começaram a dançar tango e aconteceu uma mistura muito positiva entre velhos milongueros, jovens que apareceram por curiosidade e alunos de dança. Eu vivi isso de perto porque nos 80 consegui, com esforço, a homologação de um curso no Centro Cultural General San Martín. No primeiro dia compareceram 400 pessoas e teve gente que ficou de fora. Algum tempo depois, os centros culturais dos bairros, do governo municipal de então, abriram turmas para oficinas de tango ${ }^{12}$.

O relato destaca o que aconteceu quando o governo municipal da cidade de Buenos Aires criou determinados espaços públicos de ensino, mencionando particularmente as primeiras oficinas de dança de tango, lecionadas por Olga Bessio durante 5 anos no Centro Cultural San Martín:

Em 84 [...] o Centro Cultural San Martín ofereceu oficinas diferentes. Naquela época, era o único Centro Cultural, não existiam os Centros de bairro nem os Centros para a terceira idade que hoje existem nas escolas. Nessa época, o San Martín começou a oferecer oficinas de folclore e de outras coisas. Eu dizia "Por que não oferecer tango?" Disse isso para o diretor da área de dança. E ele disse: "Não, não, porque o tango não

\footnotetext{
${ }^{11}$ Diversos estudos realizados na América Latina chamam a atenção para o papel das políticas culturais em relação a diferentes expressões da cultura popular (GARCÍA CANCLINI, 1987; GUSS, 1996; WINOCUR, 1996).

${ }^{12}$ Entrevista de Olga Besio para a revista El Tangauta, n. 174, 2009.
} 
pode ser ensinado [risos]". É claro, é algo que de certo modo é transmitido por um caminho cultural espontâneo, mas pode ser ensinado, sim, absolutamente tudo pode ser ensinado, desde que seja feito de maneira adequada. Insisti tanto, que [o diretor] disse "Está bem, faça por um mês". Como querendo dizer "Tudo bem, não é grave, afinal você vai se dar mal" [risos $]^{13}$.

Como sugere esta professora, apesar de as oficinas de dança de tango não serem muito comuns, pois, para algumas pessoas, "o tango não pode ser ensinado", a partir de 1984 surgiram diferentes âmbitos públicos de ensino na cidade. Naquela época, foi criado o Programa Cultural en Barrios ${ }^{14}$, uma política executada pela Secretaria de Cultura da Municipalidade de Buenos Aires. Em diferentes bairros da cidade, o programa implementa centros culturais, nos quais são realizadas oficinas de tango, entre outras atividades. Uma das oficinas, localizada num centro cultural do bairro San Telmo, foi analisada no final da década de 1980 pelo antropólogo Fernando Rabossi (1997). Na descrição etnográfica, o autor assinala que esse centro cultural era frequentado por um público heterogêneo, que incluía diferentes faixas etárias e diversos setores sociais. O autor sublinha também que no centro cultural eram criados grupos de amizade, surgiam vínculos pessoais e eram organizadas festas e visitas a salas de dança da região. Rabossi menciona que um dos motivos pelos quais as pessoas frequentavam a oficina de tango era a gratuidade das aulas, que eram realizadas em espaços abertos, públicos e de fácil acesso, localizados em escolas de ensino básico ou centros educativos municipais. Além dos espaços públicos utilizados para as oficinas, o autor assinala a presença de pequenos empreendimentos em outros âmbitos, como sedes de partido, sociedades de fomento e clubes sociais.

Ao que parece, os distintos espaços de ensino, presentes sob a figura de "aulas" e "oficinas" em diferentes estabelecimentos, funcionaram como uma efetiva via de acesso de muitos dos novos atores que se aproximavam pela primeira vez do tango. Apesar de tais atores estarem representados por setores

\footnotetext{
13 Entrevista disponível em: https://bit.ly/2PbkHZ9. Acesso em: 6 maio 2014.

${ }_{14}$ Para uma análise desse programa, vide Winocur (1996), Rabossi (1997).
} 
juvenis, não era infrequente a incorporação de uma geração mais velha, de 30 ou 40 anos, assim como de alguns e algumas milongueros(as) de idade avançada que, por diferentes motivos, haviam abandonado a "pista" e retomavam a prática da dança nos novos âmbitos de ensino.

Além dos novos espaços para realizar as oficinas que surgiram nos centros culturais de bairro ${ }^{15}$, apareceram outros âmbitos de ensino e prática de dança, nos quais convergiram atores sociais heterogêneos e com diferentes trajetórias. Para citar apenas um exemplo: no final da década de 1980, por exemplo, iniciaram-se aulas regulares, dando início à "prática" ${ }^{16}$ num espaço onde, anteriormente, o célebre milonguero "Pepito" Avellaneda havia dado aula. Esse local, conhecido como a "prática de Cochabamba", ou simplesmente "Cochabamba", está localizado no salão do Clube Social e Desportivo General Belgrano, na rua Cochabamba, $444^{17}$. A professora de tango Lidia Ferrari lembra de Cochabamba:

Fazíamos encontros lá. Alguns de nós já circulávamos, mais cedo ou mais tarde, pelos mesmos locais. Em Cochabamba, dançavam "milongueros" que gostavam de dançar todos os dias, como Teté, Héctor Chidíchimo e outros cujo nome não me lembro, porque nesse local não importava o nome, a profissão ou a origem, somente importava o tango. Lá estava quem depois se tornaria professor, inventor, experimentador, dançarino profissional, quem depois passou a se chamar de tango milonguero, quem depois passou a se chamar do tango novo, quem depois passou a se chamar de nenhuma maneira... o pessoal famoso e o menos famoso... os que povoaram diferentes partes do mundo [...] estavam lá para praticar, poucos praticavam visando a profissionalização. A maioria éramos amadores, nada mais (FERRARI, 2011, p. 94).

Como vemos, no final da década de 1980 e início de 1990, a cena da dança incluía novos âmbitos de aprendizado e prática para além dos centros culturais,

\footnotetext{
15 Paralelamente à emergência de atividades nos centros culturais, funcionavam em Buenos Aires outros espaços mais tradicionais de dança, localizados, por exemplo, no clube Sin Rumbo, na sala Canning, no clube Glorias Argentinas, entre outros.

${ }^{16}$ Chamamos de "prática" de tango, um evento destinado ao treinamento, ensaio, pesquisa e troca de ideias em torno da dança, em alguns casos, com o auxílio de professores. Tais encontros podem não estar conforme os códigos de comportamento habituais nas milongas.

${ }_{17}$ Gustavo Naveira, junto a Olga Besio, Domingo Pugliese e Esther Amelio foram responsáveis pela prática e as aulas.
} 
frequentados por pessoas que se aproximavam pela primeira vez ao tango e nos quais ocorria uma troca fluída entre "novos" e "velhos" praticantes. Desse modo, parece que a partir do surgimento de tais âmbitos, os quais poderíamos caracterizar como mais "descontraídos" e abertos, surge um incipiente interesse na dança, por parte de novos atores.

Em síntese, durante as décadas de 1980 e 1990, foi comum a emergência de âmbitos relativamente inovadores, como aulas, oficinas, práticas e milon$\operatorname{gas}^{18}$. Particularmente na década de 1990, o processo de ampliação do tango foi estimulado pelo crescimento de âmbitos formais de ensino que facilitaram o acesso à dança. Com o passar do tempo, aqueles que começaram como principiantes e aprendizes nas aulas e oficinas, gradativamente tornaram-se professores. Em certos casos, alguns deles começaram a sistematizar os métodos de ensino, surgindo, assim, diversas escolas, academias e professores que ensinam a dançar tango por meio de métodos e técnicas específicas. $\mathrm{O}$ processo de codificação e elaboração de didáticas da dança do tango, resultou em mudanças nos modos da dança de salão, que originaram estilos diferenciados e novas denominações para dar conta das variações estilísticas (MOREL, 2011). Como afirma Carozzi (2015, p. 172):

as oficinas de tango, que contaram com o apoio e até com a gestão do Governo da Cidade, parecem ter promovido a reconstituição inicial das milongas portenhas (ALLEN, 1997). Posteriormente, o surgimento e propagação de aulas coletivas mistas resultaram na renovação de métodos de ensino, em diante adaptados a um segmento da população que possuía um maior nível de educação formal, quando comparado ao segmento que frequentava as milongas até então. Essa revolução didática desempenhou um papel central na propagação de dançarinos e na redefinição dos "estilos" da dança, que apareceram vinculados aos métodos de ensino desenvolvidos.

\footnotetext{
18 Durante a década de 1990, diversificaram-se os circuitos e espaços de dança na cidade, consolidando assim a ampliação do campo da dança. Desse modo, além das milongas tradicionais existentes, surgiram novas milongas, como Parakultural, Trastienda, Club Almagro, Gricel e Viruta (PUJOL, 1999).
} 
Assim, a consolidação de novas modalidades de ensino por meio de aulas coletivas e mistas, processo que, como afirma a antropóloga María Julia Carozzi (2015), representou uma "revolução didática" na transmissão da dança, favoreceu a gradativa reconstituição das milongas a nível local, assim como contribuiu para uma maior aproximação de novos segmentos da população à dança do tango.

\section{ACETA: PRESERVANDO E TRANSMITINDO A DANÇA DOS "VELHOS MILONGUEROS"}

Em 2004, a Secretaria de Cultura da Presidência criou um programa chamado Academia de Estilos de Tango Argentino (Aceta), com o propósito de fomentar a "preservação" e "transmissão" dos principais estilos de dança social do tango nas gerações de jovens ${ }^{19}$. Essa iniciativa foi apresentada à Secretaria por Silvana Grill, Patricia Lamberti e Ramiro Gigliotti, dançarinos e professores de tango e integrantes de uma geração formada na dança de tango nas décadas de 80 e 90. Esses(as) professores(as) e dançarinos(as) consideravam que haviam experimentado um processo muito especial de formação na dança, pois tiveram contato direto e aprenderam com os milongueros mais antigos. Em palavras de uma das responsáveis pela Aceta:

o que nós recebemos nessa época era o que havia nesse momento [quando comecei a dançar tango], ou seja, o que tínhamos era a geração de adultos mais velhos, que tinham conservado o tango intato neles e o transportaram dos anos 50 para os 80 e pouco, isso é o que nós

\footnotetext{
19 Alguns dos objetivos da Academia eram: 1 - Preservar os conhecimentos e experiências dos milongueros mais destacados; 2 - Transmitir às novas gerações de dançarinos os principais estilos do tango de salão; 3 - Estimular os jovens dançarinos a gerar seu estilo próprio; 4 - Registrar, de maneira organizada e sistemática as distintas técnicas, figuras e estilos do tango de salão; e 5 - Promover a divulgação e continuidade desses conhecimentos. Disponível em: http://bit.ly/306oR9y. Acesso em: 30 abr. 2016. A criação de Aceta foi, em parte, inspirada no programa chamado "Orquesta Escuela de Tango", criado no início de 2000 pelo governo da cidade, com o objetivo de formar jovens músicos na prática instrumental, tentando resgatar a experiência e os estilos musicais das orquestras típicas.
} 
recebemos, por isso acho que nós somos uma geração praticamente de transmissão ${ }^{20}$.

Ao valorizar essa experiência de formação que haviam "recebido" de gerações anteriores, os organizadores da Aceta buscavam que as gerações no início de 2000 pudessem ter contato de primeira mão com os "velhos milongueros". Para isso, justificavam a iniciativa da seguinte maneira:

Os saberes e experiências da dança popular do tango são um tesouro disperso e fragmentado que atualmente está sob risco de desaparição. Os velhos milongueros são testemunha viva de estilos, vivências, passos e condutas culturais que não ficaram registradas de maneira organizada, e que constituem um verdadeiro patrimônio intangível. A preservação e transmissão desse legado é a tarefa fundamental da $\mathrm{ACETA}^{21}$.

Um diferencial deste programa em relação aos anteriores é a sua incorporação no discurso patrimonializador ${ }^{22}$. De maneira geral, a partir da década de 1980, organizações internacionais como a Organização das Nações Unidas para a Educação, a Ciência e a Cultura (Unesco), vêm chamando a atenção sobre o risco de desaparecimento das culturas tradicionais a nível global, instando a reconhecer e preservar os saberes locais (ABREU, 2014). Uma vez que os estados nacionais endossaram os postulados da Unesco, principalmente a partir da primeira década do século XXI, emergiram novas dinâmicas patrimoniais e ações de salvaguarda associadas à promoção do patrimônio cultural denominado “intangível” ou “imaterial”, noção que, em um sentido amplo, é utilizada para definir e classificar práticas performativas diversas, como danças, músicas, rituais, artesanato, cerimônias ou narrativas, entre outras múltiplas formas de expressão. As novas políticas de patrimonialização pressupõem distintos modos de intervenção formal, que incluem a candidatura das formas

\footnotetext{
20 Entrevista concedida a Patricia Lamberti em 25 ago. 2016.

${ }^{21}$ Grifo no original. Disponível em: http://bit.ly/306oR9y. Acesso em: 30 abr. 2016.

22 No final da década de 1990, o tango foi declarado patrimônio cultural tanto no nível municipal quanto nacional. Morel (2009) analisa o processo de ativação patrimonial.
} 
de expressão diante e através de determinadas organizações oficiais, a nível local, nacional ou internacional, até a implementação de projetos e programas de salvaguarda que busquem garantir a preservação, sustentabilidade e continuidade das expressões singulares ao longo do tempo.

Que tipo de prática de preservação e transmissão foi implementada por meio da Aceta? Fundamentalmente, essa academia ofertava um curso gratuito a cada ano. Para isso, eram escolhidas 40 duplas de dançarinos jovens (que tinham de 18 a 35 anos) por meio de um processo de seleção nacional. O curso tinha como convidados distintos(as) milongueros(as) destacados(as), para que eles ou elas pudessem transmitir seus saberes e habilidades aos alunos, assim como eram organizadas palestras e entrevistas, nas quais esses ou essas milongueros(as) contavam suas histórias, experiências pessoais e anedotas. Em contrapartida, os alunos davam aulas de dança abertas e gratuitas, assim como organizavam apresentações em eventos públicos. Em 2006, uma das responsáveis da Academia exaltava assim a continuidade do projeto:

Hoje nós estamos trabalhando com mais de quarenta professores afirma Silvana Grill. Desde o início, buscamos contar com pessoas cujo acesso não era simples, uma boa quantidade de milongueros conhecidos, maravilhosos, e que hoje são mestres. Realmente havia muitos milongueros que nunca haviam dado aula e que não tinham interesse em fazer isso. Descobri eles em locais afastados, em Avellaneda, em Lanús, onde aliás ainda permanece o lado festivo do ambiente do tango [...] A pergunta era: como essas pessoas que não tinham nenhuma experiência pedagógica podiam ensinar? Resolvemos essa questão convidando [além dos milongueros] professores de tango popular que tivessem experiência de ensino (GRILL, 2006).

Como assinalado no relato, um desafio importante que surgiu a partir da implementação da Aceta foi como transmitir saberes e práticas dos milongueros, uma vez que muitos deles não tinham demasiada experiência de ensino e inclusive em alguns casos, "nunca haviam dado aula". Para superar essa dificuldade, os responsáveis pela Aceta chamaram professores(as) que possuíam uma maior experiência na prática de ensino. Esses(as) professores(as) 
foram responsáveis pela adaptação dos saberes e práticas populares dos(as) milongueros(as) convidados(as) para um contexto institucionalizado de transmissão. Na prática, a dinâmica de trabalho abrangeu a realização de aulas e oficinas, portanto, o processo de transmissão de saberes exigiu novas metodologias de ensino de um repertório de conhecimentos incorporados na cotidianidade dos milongueros ${ }^{23}$. Nesse sentido, o papel desempenhado pelos especialistas em relação à cultura popular costuma ser a mediação. Ou seja, a intervenção deles permite "sistematizar" e "organizar" os saberes e práticas populares de maneira que eles possam ser transmitidos, apropriados, praticados e colocados em circulação para novos atores e contextos sociais.

Entretanto, é importante assinalar que os milongueros convidados também forneceram sua própria visão e conceitos de aprendizado:

curtiam muito, as aulas eram realmente divertidas [...] o ambiente lúdico, de brincadeira, o ambiente para se divertir é o ambiente de aprendizado que eles conheciam, eles não recebiam por isso, o sustento deles nunca dependeu do tango, então podiam descontrair e se divertir, eles aprendiam se divertindo, não conheciam outra forma, eles levaram isso a ACETA [...] surgiu algo que mexeu com todas as turmas ${ }^{24}$.

Podemos afirmar que a oportunidade de encontro e troca estimulada pela Aceta e destinada aos mais velhos e aos jovens instigou um rico processo de reflexão e valorização dos saberes populares. Do ponto de vista dos "velhos milongueros" que participaram da Aceta, a incorporação de conhecimentos e práticas deles num contexto institucionalizado, assim como os vínculos afetivos estabelecidos com diferentes grupos de jovens aprendizes, acabaram contribuindo para uma maior valorização das habilidades na dança, fortalecendo a autoestima e reconhecimento dos mais velhos. Além disso, os mais

\footnotetext{
${ }^{23}$ Vale lembrar que, como assinalado por García Canclini (2010, p. 72), as classes populares contam com menos possibilidades de transformar suas expressões e bens culturais em patrimônio legitimado e reconhecido pela sociedade, seja por: 1 - a dificuldade de acumulação histórica; 2 - a dificuldade em transformar essas expressões e saberes em saberes objetivados que ultrapassem a transmissão oral e 3 dificuldade para sua divulgação institucional e pesquisa sistemática.

${ }^{24}$ Entrevista concedida a Patricia Lamberti em 25 de agosto de 2016.
} 
velhos eram considerados pelos jovens como possuidores de estilos e modos de dança "únicos", estimulando, em muitos casos, a volta à ativa de muitos dos mais velhos no final da vida.

Naqueles anos, a Aceta foi o único projeto com apoio estatal focado no fortalecimento da preservação e transmissão do patrimônio "vivo" do tango dançado em Buenos Aires. Todavia, esse programa oficial foi desativado em 2007 devido à falta de financiamento e apesar das intenções de continuidade dos responsáveis. Em agosto de 2015, após vários anos de inatividade, o programa foi reinaugurado sob o patrocínio do Ministério de Cultura, contando com os mesmos responsáveis (Silvana Grill, Patricia Lamberti e Ramiro Gigliotti), porém sob o rótulo de Espaço Nacional de Tango Argentino (Enta), integrado ao recém inaugurado Centro Cultural Kirchner. Na primeira seleção pública, concorreram mais de 200 duplas de todo o país e foram selecionadas 45 para integrar o Programa.

Entretanto, alguns meses depois, em abril de 2016, após a saída de funcionários de alto nível no Ministério ${ }^{25}$, a nova equipe optou pela não continuidade do programa. Para além dos motivos e conjunturas políticas subjacentes a essa decisão $0^{26}$, a falta de apoio de programas desse tipo está relacionada ao fato dessas políticas públicas serem consideradas pouco lucrativas para as autoridades governamentais, como afirma uma das responsáveis de Aceta e de Enta:

a questão desses programas educativos é que eles nunca têm muita visibilidade para os governos. Para começar, não são recitais massivos. Além disso, nos programas educativos, o investimento e os resultados são de longo prazo [...] por isso, as inciativas em balé são criadas, pois mostram resultados em pouco tempo. Os programas educativos [como Aceta e Enta] não apresentam resultados numa única gestão, porque envolvem o longo prazo [...] portanto, em geral, não existem investimentos muito importantes e econômicos nestes programas ${ }^{27}$.

\footnotetext{
${ }^{25}$ Em dezembro de 2015, finalizou o período de governo de Cristina Fernández Kirchner. Mauricio Macri tomou posse como novo presidente da Argentina.

${ }^{26}$ De modo geral, grande parte dos programas e atividades desenvolvidos pela gestão política anterior, enquadrados no Centro Cultural Kirchner, foram congelados ou desativados no governo de Mauricio Macri.

27 Entrevista concedida a Patricia Lamberti em 25 de agosto de 2016.
} 
É interessante observar que, na época da interrupção do Enta, o Ministério de Cultura lançava, em abril de 2016, o edital do Programa Seleção Federal de Tango - Dança, o qual buscava promover uma maior profissionalização da dança de tango a nível federal. Durante um ano, a Seleção objetivou a capacitação de 24 duplas profissionais ou semiprofissionais - cada dupla representando uma província do país -, com vistas a montar e exibir um espetáculo como resultado final do processo. Sobre isso, uma matéria jornalística assinala que:

A Seleção é uma iniciativa do Plano Nacional de Promoção do Tango, presente desde 2011 no Ministério de Cultura, e fez a primeira apresentação em novembro do ano passado [2015], num único espetáculo que lotou a sala do CCK [Centro Cultural Kirchner] e instigou a continuidade do Projeto (EN BUSCA..., 2016, p. 10).

Assim, vemos que o sucesso de uma política cultural é avaliado conforme a repercussão de eventos espetacularizados. Como afirma Cruces (1998), um aspecto inevitável e problemático no processo de "objetivar" certas formas culturais populares é o predomínio da sua espetacularização, transformando o processo em um modelo muito afastado das práticas dos produtores cotidianos. A partir das considerações mencionadas anteriormente, constatamos a existência de um campo de tensão nas políticas culturais contemporâneas. Estamos falando de um plano de ação mais orientado pelas decisões que privilegiam projetos associados à produção de espetáculos, que pelas experiências educativas que promovem processos de transmissão de determinadas memórias, saberes e formas de expressão cultural relacionadas ao patrimônio de caráter imaterial.

\section{CONSIDERAÇÕES FINAIS}

O momento histórico pós-ditatorial da Argentina pressupôs um contexto sociopolítico de debate em torno das grandes expectativas pela volta da democracia. Lembremos que a ditadura militar não apenas aniquilou espaços de liberdade, por meio do medo, a repressão e desaparição de pessoas, como 
também praticamente suprimiu a prática de certas tradições populares urbanas (INFANTINO; MOREL, 2015). A partir dessa conjuntura política, no presente artigo buscamos entender o desenvolvimento de um processo inicial de ressurgimento da dança, a partir de um conjunto de experiências e narrativas relacionadas a atores e políticas culturais locais. Como vimos, esse processo foi estimulado, inicialmente, por uma renovada inclinação da população local para o aprendizado da dança do tango e por um cenário de emergência de novos espaços de ensino de certos saberes e práticas que até essa época eram transmitidos e ensinados informalmente. Ao mesmo tempo, alguns professores(as) e dançarinos(as) começaram a dar oficinas e aulas de dança em espaços institucionais, propiciando a aparição de novas didáticas, modos de aprendizado e transmissão associados ao ensino. Com o passar do tempo, essas experiências colaboraram e fortaleceram-se mutuamente, gerando diferentes possibilidades de formação de novos espaços de acesso à prática da dança e facilitando, na década de 1990, a ampliação da dança em novos segmentos da população local. Como apontado por Oliven (1982), nos movimentos de apropriação de expressões culturais populares por parte de novos setores e classes sociais, ocorre uma recodificação, propiciada pela circulação em novos circuitos que atribuem a essas expressões novos significados e valores simbólicos.

É interessante observar que o processo inicial de revitalização da dança, registrado a partir da década de 1980 e início da de 1990, foi principalmente enquadrado nas oficinas promovidas por alguns centros culturais do governo da cidade. De qualquer modo, em outros trabalhos assinalamos alguns dos limites nas políticas implementadas nesse período (INFANTINO; MOREL, 2015), caracterizadas pelo escasso, instável e disperso apoio governamental. Consideramos que foi a partir do final da década de 1990 que tal situação mudou de forma ostensiva, numa época de consolidação de um novo paradigma em torno ao papel da cultura e o patrimônio nas agendas políticas locais, nacionais e internacionais (MOREL, 2009), a partir da redescoberta dos saberes populares e das tradições locais, sob o rutilante rótulo de patrimônio "intangível” ou "imaterial". Desse modo, o redirecionamento produzido 
a respeito do patrimônio favoreceu a emergência de novas políticas culturais estatais favoráveis à preservação, à promoção e à gestão pública de determinadas tradições locais.

Esse foi o caso de Aceta e Enta, programas que implementaram projetos institucionais inovadores em relação à transmissão das práticas e saberes dos "velhos milongueros". É importante destacar que esses programas geraram um movimento de aproximação, reencontro e uma troca proveitosa entre gerações, construindo uma maior consciência sobre o valor das tradições e saberes locais. Portanto, aqui são mais centrais as trocas e reflexões entre gerações do que os resultados das políticas públicas ${ }^{28}$. De qualquer modo, vimos que uma tensão recorrente envolvida nos projetos vinculados ao patrimônio imaterial é dada pela precariedade e ausência de estratégias políticas que busquem privilegiar os protagonistas e os processos em si mesmos, ao invés de focarem a atenção nos resultados imediatos ou produtos finalizados. Como aponta García Canclini (1994), o campo patrimonial representa um espaço de disputa onde interagem diferentes atores sociais, que expressam contradições e conflitos em torno aos usos do patrimônio.

Afinal, apesar da ausência de uma política coerente e de longo prazo em relação à proteção do patrimônio "vivo" da dança do tango, a experiência da Aceta e do Enta parece ter contribuído para a criação de um elo entre diferentes gerações. Em outras palavras, esses programas representaram um estímulo para a transmissão dos saberes e práticas de um coletivo de milongueros locais, pelo menos a respeito das novas gerações que começaram a interessar-se no tango no início do século XXI. Por isso, parece impreterível a elaboração de políticas patrimoniais planificadas, consensualizadas, que não dependam dos mandatos políticos do momento e que garantam a participação diversa dos grupos sociais envolvidos.

\footnotetext{
${ }^{28}$ Sobre a dinâmica de patrimonialização da arte Kusiwa no Brasil, Abreu (2014, p. 16) afirma que "A riqueza desses processos parece superar qualquer resultado relativo aos próprios produtos finais. Transitando entre regimes culturais diferenciados, construindo formas de ver a si mesmos e suas tradições, redescobrindo novos aspectos de sua continuidade, valorizando os mais velhos e seus saberes".
} 


\section{REFERÊNCIAS}

1. ABREU, Regina. Dinámicas de patrimonialización y “comunidades tradicionales” en Brasil. In: CHAVES, Margarita; MONTENEGRO, Mauricio; ZAMBRANO, Marta (org.). El valor del patrimonio: mercado, políticas culturales y agenciamientos sociales. Bogotá: Instituto Colombiano de Antropología y Historia, 2014. p. 39-67. Disponível em: https://bit.ly/2GhJiYg. Acesso em: 13 dez. 2016.

2. ALLEN, Matthew Harp. Rewriting the script for South Indian dance. The Drama Review, Cambridge, MA, v. 41, n. 3, p. 63-100, 1997.

3. CAROZZI, María Julia. Más acá del triunfo en París: la revolución didáctica en la difusión del baile del tango en el cambio de milenio. Antropolítica, Niterói, n. 33, p. 25-50, 2012.

4. CAROZZI, María Julia. La revolución didáctica y la redefinición de los estilos de baile: pedagogías móviles. In: Aquí se baila el tango: una etnografía de las milongas porteñas. Buenos Aires: Siglo XXI, 2015. p. 133-173.

5. CRUCES, Francisco. Problemas en torno a la restitución del patrimonio: una visión desde la antropología. Alteridades, México, DF, v. 8, n. 16, p. 75-84, 1998.

6. EN BUSCA del Seleccionado Federal. La Milonga, Argentina, n. 123, p. 10, 2016.

7. FERRARI, Lidia. Tango: arte y misterio de un baile. Buenos Aires: Corregidor, 2011.

8. GARCIA CANCLÍNI, Néstor. Introducción: políticas culturales y crisis de desarrollo: un balance latinoamericano. In: GARCIA CANCLÍNI, Néstor (ed.). Políticas culturales en América Latina. México, DF: Grijalbo, 1987. p. 13-61.

9. GARCIA CANCLÍNI, Néstor. ¿Quiénes usan el patrimonio? Políticas culturales y participación social. In: VILLAFRANCA, Jaime Cama; WITKER, Rodrigo Barra (org.). Memorias del Simposio Patrimonio y Política Cultural para el siglo XXI. México, DF: Instituto Nacional de Antropología y Historia, 1994. p. 51-68. (Colección Científica, 296).

10. GARCIA CANCLÍNI, Néstor. La sociedad sin relato: antropología y estética de la inminencia. Buenos Aires: Katz, 2010.

11. GRILL, Silvana. Danza: entrevista con Silvana Grill: melodía de arrabal. Clarín, Buenos Aires, 18 fev. 2006. Disponível em: https://bit.ly/2Gi2IfC. Acesso em: 16 abr. 2019.

12. GUSS, David. "Full speed ahead with Venezuela": the tobacco industry, nationalism and the business of popular culture. Public Culture, Durham, v. 9, n. 1, p. 33-54, 1996. 
13. INFANTINO, Julieta; MOREL, Hernán. Circo, murga e tango em Buenos Aires: processos de ressurgimento e Arte Popular da pós-ditadura (1983). Antropolítica, Niterói, n. 38, p. 321-347, 2015.

14. MOREL, Hernán. El giro patrimonial del tango: políticas oficiales, turismo y campeonatos de baile en la ciudad de Buenos Aires. Cuadernos de Antropología Social, Buenos Aires, n. 30, p. 155-172, 2009.

15. MOREL, Hernán. Estilos de baile en el tango salón: una aproximación a través de sus evaluaciones verbales. In: CAROZZI, María Julia (org.). Las palabras y los pasos: etnografías de la danza en la ciudad. Buenos Aires: Gorla, 2011.p. 189-222.

16. MOREL, Hernán. Vuelve el tango: "Tango Argentino" y las narrativas sobre el resurgimiento del baile en Buenos Aires. Revista del Museo de Antropología, Córdoba, v. 5, n. 1, p. 77-88, 2012.

17. OCHS, Elinor. Narrativa. In: VAN DIJK, Teun A. (org.). El discurso como estructura y proceso: estudios del discurso I: una introducción multidisciplinaria. Barcelona: Gedisa, 2000. p. 271-302.

18. OLIVEN, Ruben George. As metamorfoses da cultura brasileira. In: OLIVEN, Ruben George. Violência e cultura no Brasil. Petrópolis: Vozes, 1982. p. 61-73.

19. PUJOL, Sergio. Historia del baile. Buenos Aires: Emecé, 1999.

20. RABOSSI, Fernando. La cultura y sus políticas: análisis del programa cultural en barrios. 1997. Tese (Licenciatura em Ciências Antropológicas) - Facultad de Filosofía y Letras, Universidad de Buenos Aires, Buenos Aires, 1997.

21. WINOCUR, Rosalía. De las políticas a los barrios: programas culturales y participación popular. Buenos Aires: Flacso: Miño y Dávila, 1996. 